\title{
Anthrobiogeochemical cycles: A Russian perspective
}

\section{GIULIA RISPOLI}

Max Planck Institute for the History of Science

Presenting Author: giuliarispoli@gmail.com

Anthropogenic alterations of Earth's geochemistry have been so profound in the last century that the new definition of anthrobiogeochemical cycles would grasp more effectively the interdependence of these cycles with economic activities such as mining or manufacturing. The proposed paper traces back the idea of anthrobiogeochemical cycles in the work of Russian geochemist Vladimir I. Vernadsky and his school in the early 20th century. Vernadsky wrote that the face of the planet - the biosphere - is being sharply changed chemically by humanity both consciously and even more so unconsciously. Our species is changing physically and chemically the atmosphere and other parts of nature. As a result of the growth of human culture (especially in the 20th century), the shores of the sea and parts of the ocean are changing more and more radically (chemically and biologically). He concludes that humans must now take greater measures to conserve for future generations the riches of the oceans that belong to no one. In this early elaboration, the biosphere seems to possess similar features to the contemporary Earth system notion. Moreover, Vernadsky investigated human biogeochemical manipulation of the biosphere, which is nowadays referred to as the Earth's "critical zone" - a heterogeneous space of interaction of biogeochemical components. 